This item was submitted to Loughborough's Research Repository by the author.

Items in Figshare are protected by copyright, with all rights reserved, unless otherwise indicated.

\title{
Developing social theory using critical realism
}

PLEASE CITE THE PUBLISHED VERSION

http://dx.doi.org/10.1179/1476743014Z.00000000047

\section{PUBLISHER}

(c) W. S. Maney \& Son Ltd

\section{VERSION}

AM (Accepted Manuscript)

\section{PUBLISHER STATEMENT}

This work is made available according to the conditions of the Creative Commons Attribution-NonCommercialNoDerivatives 4.0 International (CC BY-NC-ND 4.0) licence. Full details of this licence are available at: https://creativecommons.org/licenses/by-nc-nd/4.0/

\section{LICENCE}

CC BY-NC-ND 4.0

\section{REPOSITORY RECORD}

Elder-Vass, Dave. 2019. “Developing Social Theory Using Critical Realism”. figshare. https://hdl.handle.net/2134/17425. 
DEBATE

\title{
Developing Social Theory Using Critical Realism
}

\author{
Dave Elder-Vass \\ Loughborough University, UK
}

Note: This is a pre-publication version of a paper published in the Journal of Critical Realism. It may differ slightly from the published version. Please cite as: Elder-Vass, D. (2015) 'Developing social theory using critical realism', Journal of Critical Realism 14:1, 80-92., and refer to the published version for the final wording and pagination.

How should critical realists do social theory? This paper considers several issues raised by this question, in response to Jamie Morgan's recent article, and comments on his discussion of norm circles.

KEYWORDS norm circles, social construction, culture, social theory

\section{Introduction}

Jamie Morgan's recent paper in this journal uses a discussion of my book The Reality of Social Construction to grapple perceptively with a range of interesting and constructive questions about how realists should approach social theory. ${ }^{1}$ This response seeks primarily to engage with some of those broad open questions, exploring two groups of issues. First, how should we approach the task of making sense of the enormous complexity of social phenomena like normativity and their impact on social events? Morgan ${ }^{2}$ questions the strategy of seeking simplicity first and adding complexity as we develop the analysis, which I shall defend. Second, how should we treat relevant previous realist theoretical work? Morgan seems to oppose reframings of the same conceptual territory that are not explicitly justified by improved explanatory purchase upon social reality. I will disagree, while nevertheless pleading innocent to the non-crime. ${ }^{3}$

To clarify the context, let me also make a few introductory comments about The Reality of Social Construction. The central argument of the book is that realism and social constructionism are entirely compatible, and indeed mutually supportive if understood properly. This argument is

\footnotetext{
${ }^{1}$ Morgan 2014, Elder-Vass 2012.

${ }^{2}$ We would prefer to refer to each other as Jamie and Dave but academic convention dictates otherwise!

${ }^{3}$ Morgan also makes a number of criticisms of the book, though these are balanced by some kind compliments. In the interests of readability and focus I have responded here only to those criticisms that are significant for the main thread of the argument below. That doesn't mean that I accept the others.
} 
supported by the use of critical realism to develop a social ontology of various normative/cultural phenomena including social institutions, language, discourse, and knowledge. This provides a basis for showing how such forces can participate in processes of social construction, but also a basis for rejecting some of the more extreme, and indeed anti-realist, claims of social constructionists. Morgan suggests that it is a book about norm circles, the social entities that I consider causally responsible for normativity. This is half right, in that the social ontologies it develops all make use of this concept, although it would be more accurate to say that it is a book that uses the concept of norm circles in the course of building an argument about social construction, and in the process further develops my analysis of them. Having portrayed it as a book about norm circles, Morgan complains that the book's argumentation strategy is not primarily oriented to elaborating the concept of the norm circle as it applies to real social cases and the issues that this generates. ${ }^{4} \mathrm{He}$ 's right. It isn't. It's oriented to theorizing social construction and to engaging with the social constructionist tradition. Nevertheless, I believe that it does develop the concept of norm circles in a number of useful and empirically relevant ways, and I am more than happy to defend its argumentation strategy.

\section{Eggs and chickens}

The problem of explaining massively complex phenomena raises several distinct though inter-related issues. Morgan approaches these issues by questioning my use of the concept of norm circles to explain normative phenomena. Essentially, norm circles are groups of people, and I argue that we follow normative standards, when we do, as a result of the influence that these groups have on us. ${ }^{5}$ Morgan gives a largely accurate and sympathetic account of this theory, but then suggests that it starts from the wrong end of the problem of normativity. He thinks that normativity is inherently complex and that its effects on us are a consequence of that complexity, whereas my argument tries 'to solve the problem of norms by creating a primitive descriptor ${ }^{6}$ - the norm circle as a buildingblock concept - and then seeks to add the complexity afterwards.

This argument raises at least two kinds of problems. Let me call them the problem of retroduction and retrodiction, which this section will discuss, and the problem of complex/relational mechanisms, to be covered in the next one. Anyone who is reasonably well read in critical realism will understand the concepts of retroduction and retrodiction, which arise from our understanding of events as multiply determined. ${ }^{7}$ Given that events are always the outcome of multiple interacting causal powers, explaining them requires two activities. In retroduction we identify individual causal powers and the mechanisms that produce them, and in retrodiction we investigate what mix of causal powers interacted in what way to produce any particular event.

The problem of retroduction and retrodiction can be expressed most simply as a problem of sequence: which do we do first? This looks very much like a classic chicken-and-egg problem, in that it's hard to see how we can do either unless we have already done the other one first. If we are going to retrodict the set of causes contributing to an event, it seems that we need to have a set of prior retroductions that we can draw on and combine. On the other hand, if we are to retroduce a particular mechanism, it seems that we must already have done some retrodictions that identified

\footnotetext{
${ }^{4}$ Morgan 2014, 131-2.

${ }^{5}$ For the full argument, see Elder-Vass 2010a, chapter 6 and/or Elder-Vass 2012, chapters 2-3.

${ }^{6}$ Morgan 2014, 127.

${ }^{7}$ Bhaskar 1975, 109-11; Elder-Vass 2012, 15-19.
} 
that there was a power to be explained. ${ }^{8}$ If we had to start our analysis of some phenomenon from a position of complete ignorance in which we merely observed empirical events it is hard to see how we could ever get started on this kind of explanatory endeavour.

In practice, however, we never do start from a position of complete ignorance. Methodological positivists might like to imagine the neutral observer as a blank slate, applying reason to evidence to derive scientific conclusions untainted by prior assumptions. But there is no such observer and no such science. We always have reasons for investigating our topics of interest, and both these reasons and our investigations always depend on prior knowledge of those topics. In the case of social theory this is typically derived from prior experience of the phenomena concerned and exposure to both lay thinking about the topic and the related literature. We always begin, then, with a fund of assumptions about the sorts of causal forces that might be at work.

The temptation at this point is this: to take our assumptions about the kinds of things that operate in the social world and the kinds of influence they can have (perhaps even labelling them as causal powers) and use them to develop retrodictive explanations of social events. This is the world of empiricist explanations based on unchallenged implicit ontologies. Sometimes they may seem quite realist. Sometimes they may even be right, when our assumptions happen to map onto a locally accurate understanding of the causal forces concerned. I expect we all develop such explanations from time to time, in our everyday lives as well as under the guise of social science. And this isn't necessarily a bad strategy: the lay and academic knowledge upon which we rely is often based on huge amounts of intelligently analysed experience. But in some cases that background knowledge rests on false ontological assumptions, and this strategy leaves those assumptions entirely unchallenged. My feeling is that far too much social science is conducted on such a basis: what we may call retrodiction without retroduction.

Hence in my work I have sought to be more rigorous about the ontological basis of causal powers. The only satisfactory way to do so in methodological terms is to take an iterative approach (a central theme of my earlier writing on realist methodology). ${ }^{9}$ But any account of an investigation must start somewhere. Exposition is an activity distinct from investigation, and exposition never follows the same sequence or logic (or lack of logic) as the investigation it purports to describe. My expository strategy in these books has been driven by the belief that existing social science is far too prone to start from retrodiction without ever giving satisfactory accounts of the mechanisms it relies on. Therefore I deliberately start from the other end, focusing on retroduction, while making clear that this is part of a larger strategy, and from time to time reminding the reader of the need for retrodiction and the ways in which other forces may interfere with the one currently in focus.

It is in the nature of retroduction as I understand it that the analyst should develop 'primitive descriptor $[\mathrm{s}]^{10}$ of the type of entity, mechanism, and power being theorized. Before one can explain the contribution that some sort of entity makes to events, one must analyse what is characteristic of entities of this kind that gives them a certain type of power to influence events. We need to know what sorts of parts, organized in what sorts of ways, are characteristic of this type of entity, and how they interact to produce the causal power concerned. If we can do so we have a good though fallible

\footnotetext{
${ }^{8}$ See Morgan 2014, 137.

${ }^{9}$ See Elder-Vass 2007 or Elder-Vass 2010a, chapter 4.

${ }^{10}$ Morgan 2014, 127.
} 
reason, compatible with the wider ontology of critical realism, for supposing that entities of this type can have such causal powers, and thus a stronger justification for suggesting that it interacts with other powers to produce some event. Of course, there may be many varieties of the entity, mechanism and power, and many variations of the ways in which they interact, but my strategy, of which Morgan perhaps disapproves, is to add that complexity later. Nor is this an indefinite deferment: the books are full of examples where I go on to do so.

\section{Complex mechanisms}

Morgan's criticism of my explanatory strategy takes a somewhat different tack, however, by suggesting that the mechanisms underlying normativity may be too complex to be reduced to primitive descriptors. He is concerned that I describe norm circles and only then introduce the multiplicity of norms, clustering, contradictions within the individual, and the dynamic nature of social relations. ${ }^{11}$ One might object (and I would!) that the order of presentation is irrelevant to questions of adequacy as long as the end result is coherent, plausible, and consistent with our empirical experience. But Morgan argues that it is fundamental to the nature of norms that they are complex, and in particular that 'they do not inhere in the individual singly, i.e. without reference or mutuality' ${ }^{\prime 2}$ and that 'the fuzziness and multiplicity of norms is a constituent of the complexity of norms as properties of people'. ${ }^{13}$

Morgan has shifted attention here away from the social determinants of normativity, which are the primary focus of my work on norm circles, towards the relations in which norms stand to each other as mental properties of individuals. He suggests that my focus on the external influences might 'inadvertently imply ${ }^{\prime 4}$ that the only way in which norms interact within the individual is additive (i.e. mutually reinforcing or cancelling out their influence on some particular action), thus obscuring the relationships between norms. The problem then would be that the isolated norm is 'a disaggregation as a solution to a relational problem' ${ }^{15}$ In other words, by treating norms singly at any stage of the analysis we eliminate a feature of their nature that is essential to theorizing them successfully.

We need to distinguish here between two questions. On the one hand, I am happy to agree with Morgan that our ontology must accurately reflect the relational characteristics of the kinds of things we are studying. An ontology that abstracted away from relational characteristics that are fundamental to the properties of the thing being analysed would be unsatisfactory. At the level of the general principle, then, there is no gap between us. On the other hand, we disagree on the application of this principle to the case of normativity.

Morgan writes as if the holding of different versions of norms by different individuals, the mutual referencing of norms, the existence of meta-norms, and the exercise of judgement and awareness in normatively-influenced decision making were issues that the norm circle approach is unable to cope with. All four, however, are in fact issues that are explicitly raised and addressed in my work in innovative ways that are thoroughly compatible with the theory of norm circles. Normativity does not necessarily produce internally identical representations of norms in multiple individuals, because

\footnotetext{
11 Morgan 2014, 125.

12 Morgan 2014, 125.

13 Morgan 2014, 126.

${ }^{14}$ Morgan 2014, 125-6.

15 Morgan 2014, 127.
} 
norm circles regulate only the observable expression of our normative dispositions, and not our internal representations of them. ${ }^{16}$ Norms may depend on each other for their meaning and for specification of the context in which they apply, which I have described using the concept of indexing norms (and thus I do not treat their interactions as purely additive). ${ }^{17}$ There can be norms that regulate which other norms should be adopted - meta-norms - which I discuss in the context of linguistic and cultural nationalism. ${ }^{18}$ And in my earlier book I have discussed agency at some length and given an extended example of how it is involved in a case where normative and other influences on an individual conflict. ${ }^{19}$

None of these phenomena requires us to abandon the theory of norm circles, or to abandon the idea that each norm circle relates to a single identifiable norm. Of course, those norms may be interrelated, but we are perfectly capable of understanding them as distinct and interrelated. Consider one of the examples of indexing norms given in the book. The social institution of property depends on a complex of different but interrelated norms, including the general norm that may be summarized as 'you may not take an object that belongs to another person without their permission,' and a series of 'indexing norms that define what objects count as belonging to another person' ${ }^{20}$ These norms interact to produce our respect for other people's property, but they are distinct from each other, and they can vary independently of one another. Music publishing companies, for example, have devoted a great deal of effort over the last decade or so to convincing us that certain arrangements of bits in the memories of our computers and smartphones count as their property, thus developing a new indexing norm that has been articulated with the more general norm regulating the use of others' property. ${ }^{21}$

Understanding such phenomena is indeed a relational problem: the relations between the different norms concerned are important, and the social relations between us and the advocates of the various norms involved are also important. But none of this complexity is lost by starting our analysis from individual norms as the products of separate norm circles. Nor does the question of whether this is a good theory turn on whether we should start with primitive descriptors: the issue is whether this particular primitive works as a description of a significant underlying mechanism.

\section{Pinning down causal power}

Here Morgan raises another concern about the theory of norm circles. Even if we grant that there are groups of people with a tendency to endorse and enforce specific norms, as he seems to do, we can question whether these groups are 'determinant for the norm'. 'Membership of a "group" (which may be no more than a category devised by the theorist) may not be the same as causal significance for a norm' ${ }^{22}$

Once again, we must separate questions of principle and application. Methodological individualists question whether groups and other social entities can have causal significance at all, but Morgan is not a methodological individualist. We can accept that there are social entities that exist and have

\footnotetext{
${ }^{16}$ Elder-Vass 2012, 50-53.

${ }^{17}$ Elder-Vass 2012, 69-73.

${ }^{18}$ Elder-Vass 2012, 166-7, 172.

${ }^{19}$ Elder-Vass 2010a, chapters 5 and 8.

${ }^{20}$ Elder-Vass 2012, 72.

${ }^{21}$ See, for example, Gillespie 2007; Lessig 2004; Strangelove 2005.

22 Morgan 2014, 122-3.
} 
causal power and still dispute whether examples exist of any particular type of social entity proposed by a scholar and if so whether they have causal power. At the level of principle, then, I do not think there is a significant difference between us here. Morgan's challenge is to question whether norm circles in particular have causal power, not to question whether social entities in general can have causal power.

One of the reasons social theory is so controversial is that we don't have reliable methods for resolving challenges like this. The minimum requirement for taking theories seriously is that they should be consistent with empirical experience. To suggest that the theory of norm circles is not, Morgan offers a hypothetical example based on caste practices to suggest that there are cases where the causal power does not rest with the norm circle. ${ }^{23}$ In this example, a person from a lower caste is coerced to conform to a caste-specific behavioural norm by members of a higher caste, and Morgan argues that 'It is curious to think of the victim here as a member of a norm circle and it is curious to think of [their act of conformity] as augmenting the norm'. ${ }^{24}$ And he adds: 'A norm circle under Elder-Vass's description can include members who are victims of norms and who are actively opposed to those norms' ${ }^{25}$ He gives this as an example of 'a host of ways in terms of which the concept of a norm circle as an emergent entity with a given causal power of augmentation is problematic and so the concept of a norm circle as defined may be one that obscures rather than clarifies'. ${ }^{26}$

Morgan states that I have defined the norm circle in a way that includes anyone who conforms to a norm ${ }^{27}$ and then argues that it is unreasonable to think of someone who is unwillingly coerced to conform to a norm as augmenting its power. But being punished for non-compliance with a norm does not make someone a member of the norm circle concerned, as I have defined the concept: they are only a member of the norm circle if they have a tendency to endorse and enforce the norm. Granted, there is a fine line here: I may take your actions as an exemplar whether you intend me to or not, and this aspect of normativity is not currently covered by the norm circle theory (the concept does already cover deliberately conspicuous conformity with a norm which is intended as an endorsement of it). But I have never suggested that someone who is coerced into conformity with a norm is thereby augmenting it. The coercers are doing that, not the coerced. Morgan is misreading my argument when he suggests it has this implication. ${ }^{28}$

Perhaps the confusion arises from a further complication: even though being coerced into conforming to a norm does not in itself make one a member of the norm circle concerned, it is possible that the same person may also act in other circumstances as a member of that norm circle. A parent, for example, may tell their children they should always tell the truth, while lying themselves on other occasions and even being punished for it.

\footnotetext{
${ }^{23}$ I take the view that hypothetical examples based on knowledge of empirical cases are a perfectly valid technique for challenging and supporting theoretical arguments in social theory, though ultimately it is important to test theory against actual empirical evidence. I use hypothetical examples extensively myself.

${ }^{24}$ Morgan 2014: 124.

${ }^{25}$ Morgan 2014: 124.

${ }^{26}$ Morgan 2014: 124.

27 See Morgan 2014, 120.

${ }^{28}$ An illustration, incidentally, of how difficult it is for artefacts to communicate ideas in the form intended by the author.
} 
To move a little closer to Morgan's example, in cases where norms are linked to systems of inequality, it is quite common for those who suffer from this inequality to endorse the norms that flow from and/or support it, whether because they are victims of ideology or for purely prudential reasons. In the ideological case, for example, some mothers may genuinely (though mistakenly) believe that women are not capable of succeeding in senior management roles and criticize their daughters for pursuing them. In the prudential case, for example, a member of a lower caste may instruct their children to avoid offending against the norms of behaviour regarding caste hierarchy, even though they disapprove of those norms, on the grounds that the children would be exposed to punishment if they breached them. An adequate account of normativity, therefore, must encompass cases where norm circles include their victims; indeed the fact that norm circles can be extended to their victims is one of the more socially significant aspects of normativity. ${ }^{29}$

Similarly, there may even be cases where members of norm circles also actively oppose the norm concerned. Clearly in the caste example I have just given, the parent is a member who at least passively opposes the norm they help to endorse, but there is no reason here yet to question that they are a member of the norm circle for it. There may be cases, however, in which those who are victims of a norm actively endorse non-compliance with the norm concerned. It is entirely possible that our lower caste parent might criticize the norms of caste, and even take part in a campaign of civil disobedience by deliberately breaching those norms, while still advising their own children to stay within those norms for their own safety. Now, of course, we have a more compromised situation. The same individual, at one time and in one context, acts as a member of the norm circle for the norm concerned, and at another acts as a member of a conflicting norm circle. But norm circles are defined in terms of tendencies to endorse or enforce a norm; in this case we may say that our parent has a tendency to endorse the norm in some circumstances and a tendency to disendorse it in others. This adds a further level of complexity to the concept that I have not considered previously, and a useful one, but does not alter the core of the argument.

These particular cases, then, do not provide grounds for dismissing the theory of norm circles on grounds of empirical inadequacy, but this is still not enough to fully meet Morgan's challenge. Even if the theory of norm circles is fully consistent with the evidence this does not in itself prove that norm circles have causal power (as is true for all such claims, of course, not just the theory of norm circles). One of the difficulties faced by all scientists is that there can be many different ways of explaining the same set of empirical evidence. ${ }^{30}$ Given this, it can be difficult or even impossible to give empirical grounds for preferring one set of explanations over another (though some theories can be shown to be wrong, with a reasonable degree of confidence). If there are many theories consistent with the evidence, we have to find further ways of differentiating between them. The classic scientific approach is to devise empirical tests that differentiate between rival theories, which essentially extend the evidence base used in assessment of empirical adequacy. No doubt it would be useful to find rival theories of normativity and compare them with the theory of norm circles, devising suitable empirical tests if necessary and possible. However, there is no guarantee that such tests could be devised, particularly in the context of the social sciences where theories rarely

\footnotetext{
${ }^{29}$ I hope the reader will recognize this as an example of 'the exploration of nuance in terms of its relevance for reality ... rather than issues of realism': Morgan 2014: 129.

${ }^{30}$ The Duhem-Quine thesis: Stanford 2013.
} 
generate strong predictions that can be used to compare them. Nor could they ever prove the point at issue here.

How, then, could we provide further support for a social theory, support that might help us resist Morgan's challenge that norm circles may be a theorist's construction with no real causal significance? One approach is to test for consistency with our other well-founded beliefs and for internal consistency with the rest of the theorist's claims. Recognizing this, one focus of my work has been to develop a set of claims that are consistent across several layers of theory. ${ }^{31}$ In particular, a theorist's social ontology should be consistent, not only with empirical evidence, but also with a convincing general ontology. In an attempt to achieve that consistency in my own work, I have developed a reasonably precise formulation of the critical realist ontology of emergent causal powers, in which such powers are the product of mechanisms, and such mechanisms take the form of processes of interaction between the parts of the entity possessing the power. Given this general ontology, it is reasonable to expect that explanations of causal powers should be supported by plausible theories of the mechanisms behind them. In the case of norm circles, I have developed a careful account of the ways in which the interactions between members of the norm circle produce an emergent collective power that would not exist in the absence of the group. ${ }^{32}$ Such accounts do not guarantee the truth of the theory concerned, nor do they trump empirical considerations, but by formulating the theory in terms that make it consistent with a general ontology that itself is well justified they do provide further reasons to believe that the theory may be sound.

\section{Engaging with earlier realist theory}

Critical realist social theory, then, requires not only consistency with empirical evidence but also consistency with general realist ontology. One short section of my book criticizes Margaret Archer's account of culture and argues for a norm circles theory of culture instead, primarily on the grounds that I do not find Archer's Cultural System consistent with the kind of materialism I believe to be required by critical realist ontology. ${ }^{33}$ Morgan takes this as an example of a more widespread fault in realist theorizing: the fault of concentrating on 'the apparent weaknesses of other conceptualizations to create space for one's own ${ }^{\prime 34}$ with the result that the discursive focus 'is first and foremost realism in terms of realism, rather than realism in terms of an identified issue of reality'.35

At first it seemed to me that his concern was that I have constructed an argument by criticizing earlier ontological theory rather than by engaging with empirical evidence. This argument plays nicely on the desire of many social scientists for scholarly writing to be directly relevant to empirical cases and preferably directly connected to primary empirical work. It does seem a little odd, though, coming from a writer in a realist tradition that has stressed the importance of ontology in social theory. Would he criticize Bhaskar for constructing his argument for real causal powers by focusing

\footnotetext{
${ }^{31}$ See Elder-Vass 2007; and Elder-Vass 2010a, chapter 4.

${ }^{32}$ See Elder-Vass 2010a, 122-130.

${ }^{33}$ Elder-Vass 2012, 41-7. For Archer's account of the Cultural System see Archer 1988 [1996], chapter 5. I have debated these questions at length with Archer herself: Archer and Elder-Vass 2012. Morgan thinks my version of materialism is too weak to rule out even astrology: Morgan 2014, 127, n. 19. On the contrary, I believe it is strong enough to rule out not only astrology but most systems of religious belief, as well as Popper's World 3 and Bhaskar's moral realism. See Elder-Vass 2012, 20 and Elder-Vass 2010b, 40-45.

${ }^{34}$ Morgan 2014, 131.

35 Morgan 2014, 131.
} 
on the weaknesses of the empiricist tradition to create space for an alternative ${ }^{36}$ Perhaps Bhaskar's work counts as philosophy rather than social theory, so he might be excused on those grounds (though it's not apparent why social theorists should be denied the opportunity to do philosophical work, if that's the issue). Would he criticize Archer for constructing the argument for analytical dualism (in part, at least) by focusing on the problem of central conflation in the work of Giddens? ${ }^{37}$ It was only after considering these questions that I realized that it's only the critical realist canon that Morgan objects to us making use of in this way; indeed this is implicit in his phrasing of the problem as discussions of 'realism in terms of realism'. And this explains why he chooses my relatively short disagreement with Archer to make the point, rather than the more substantial engagements with Searle and Foucault in other chapters: indeed he compliments my treatment of Searle. ${ }^{38}$ I find it hard to see, however, why critical realist texts should be exempt from the critical scrutiny that we give to other theoretical texts, or why they should be any less fertile as sources of productive disagreement.

I don't see how either version of the argument could be sustained. As the previous section argued, good social theory, and particularly good critical realist social theory, which after all is written in a tradition that stresses the need for ontological coherence, must be measured against both empirical fact and consistency with more abstract philosophical work. Hence it is perfectly valid for Archer, for example, to criticize Giddens for his ontological weaknesses, and to use this to develop space for her own alternative argument. Similarly, it is perfectly valid for writers in the realist tradition to criticize other writers in the same tradition on similar grounds. I find Tuukka Kaidesoja's calls for greater consistency in Bhaskar's treatment of emergence extremely valuable, for example. ${ }^{39}$ Although Kaidesoja is a philosopher rather than a social theorist, his work contributes to improving consistency across the various theoretical elements required for a critical realist social theory. Discussion of previous theory is an entirely legitimate activity which need not relate directly to empirical applications. Indeed, one of the discursive standards expected in scholarly debate is that we should engage with significant previous work related to our own, and it would be positively unreasonable and disrespectful for a realist writing about culture to fail to engage critically with Archer's important contribution.

This does not mean that we should never criticize an author for excessive theoreticism, and in saying so, I converge with those parts of Morgan's argument where he stresses that the issue here is a matter of degree. ${ }^{40}$ Such questions must always be judged relative to the context, including the author's claims about what they are actually seeking to achieve. Given the orientation of my book, it was not only justifiable but indeed necessary to engage with Archer's work on culture, whether or not that was done in purely theoretical terms. I do agree with Morgan, though, that in a book on culture the reader is entitled to expect some engagement with the concrete social phenomena as well as criticism of alternative theoretical perspectives. Had I not done so I would have felt some unease in replying to these criticisms. But in fact the whole book is, among other things, about culture as a social reality.

\footnotetext{
${ }^{36}$ Bhaskar 1975.

37 Archer 1982.

${ }^{38}$ Morgan 2014, 137.

${ }^{39}$ Kaidesoja 2009; 2013, chapter 7.

${ }^{40}$ E.g. Morgan 2014, 129.
} 
I think I can see why Morgan has missed this. As he rightly says, the book argues that there are different kinds of normative phenomena, and it discusses these separately in sections on social institutions, discourse, language and knowledge. Morgan's paper discusses the theory of norm circles in general, and then moves on to my discussion of Archer's work on culture, treating it as a discussion of just one kind of normative phenomenon, as if culture was merely one of the many phenomena I theorize using norm circles. He might then be justified in saying that I address culture purely through my discussion of Archer, since there is little else covered in the half-chapter concerned. The difficulty with his argument, though, is that culture as I describe it is not a sub-kind of normative phenomena; rather it corresponds to normative phenomena in general. ${ }^{41}$ Hence the argument that I have neglected culture in itself and focussed exclusively on a discussion of previous realist thinking on culture is mistaken, because all of the many examples discussed in the book are examples of culture. One might narrow the field to propositional culture, as Archer does in defining the Cultural System, and then argue that I have only addressed this subset in the half-chapter concerned. But propositional culture goes under a variety of names, and the sections of the book on discourse and knowledge engage with various aspects of propositional culture as a social phenomenon in some detail. Even the section on Archer, incidentally, includes a discussion of the relative merits of the norm circles and Cultural System approaches with regard to the empirical case of creationism in the United States, though if this was the only discussion of actual propositional culture in the book Morgan might have a point. ${ }^{42}$

I have no intention of reopening the substantive issues in my disagreement with Archer here, though I'm certainly open to the possibility that further development is required before we can arrive at a reasonably adequate ontology of propositional culture. Let me just say that I don't believe that the argument turns on 'a literal and narrow interpretation of what an idea is' as Morgan suggests. ${ }^{43} \mathrm{We}$ could relabel the content of books as encoded ideas, for example, to distinguish them from mental ideas that exist as mental properties of individuals, without altering the substance of my argument at all, because that argument is not about what we call the stuff that's encoded in books and other artefacts, but about the ontological nature of this stuff, and I think all the participants in this debate agree that its ontological nature is different from the nature of mental ideas. That ontological nature matters because it affects what kind of causal significance we can attribute to this stuff, and in what circumstances we can do so.

In terms of the broader questions of how realists should approach social theory, my point is that it is legitimate to discuss the question of whether Archer's account of culture (or indeed any other argument in social theory) is consistent with a certain realist philosophical framework. Such discussions can help to lead us towards an alternative theory of the same phenomena that is more consistent, therefore this is a kind of question that we should not discourage realists from discussing. At the same time, I certainly agree that any such alternative theory must also be at least as consistent with social reality if it is to represent an advance.

\section{Conclusion}

The question of social normativity is enormously complex. My book addresses many of those complexities using the theory of norm circles, but there are no doubt many more still to be

\footnotetext{
${ }^{41}$ Elder-Vass 2012, 30-31.

${ }^{42}$ Elder-Vass 2012, 46.

${ }^{43}$ Morgan 2014, 132.
} 
addressed. I am keen to consider some of those through extended empirical case studies, and in a sense that means I share Morgan's concern that more empirically oriented work is required in this area. But this does not mean that more theoretically oriented work like The Reality of Social Construction should be considered inadequate. Critical realist social theory stitches together elements of general ontology, social ontology, domain specific theory, and our understanding of empirical evidence, all of which depend on each other in a structured way, and there should be no presumption that work on any of these layers is more or less desirable than the others.

One way of thinking about progress in realist social theory is that it occurs when we develop such sets of ideas in the direction of greater consistency, both with the rest of the ideas in the set and with our experience of the empirical world, and when we extend the range of empirical phenomena that can be brought into a consistent picture. This can involve revisions in any or all of the four layers, though the integrity of the empirical evidence must always be respected (while our interpretations of it may change). This, however, is not a universal model of theory progress; apart from anything else it is generated from within a certain version of realist theory itself and other thinkers are likely to have different ways of conceiving of progress.

In my work I have tried to retroduce the mechanisms behind normativity because I am trying to run with one of Bhaskar's core ideas - that we live in a world of powers and mechanisms and that science progresses by identifying those powers and mechanisms - and apply it to the social world. If we can do that, and in a way that fits with our experience of that world, it will demonstrate a consistency between the philosophical ontology of critical realism and its social theory that I believe constitutes a kind of progress. Ultimately, however, the question of what counts as progress in realism is a matter for the realist community to judge.

\section{Acknowledgement}

I would like to thank Jamie Morgan for his careful and thoughtful attention to my work.

\section{References}

Archer, M. S. 1982. 'Morphogenesis Versus Structuration'. British Journal of Sociology 33(4): 455-83.

Archer, M. S. 1988 [1996]. Culture and Agency. 2nd edn. Cambridge: Cambridge UP.

Archer, M. S., and Elder-Vass, D. 2012. 'Cultural System or Norm Circles? An Exchange'. European Journal of Social Theory 15(1): 93-115.

Bhaskar, R. 1975. A Realist Theory of Science. 1st edn. Leeds: Leeds Books.

Elder-Vass, D. 2007. 'A Method for Social Ontology'. Journal of Critical Realism 6(2): 226-49.

Elder-Vass, D. 2010a. The Causal Power of Social Structures. Cambridge: Cambridge UP.

Elder-Vass, D. 2010b. 'Realist Critique without Ethical Naturalism or Moral Realism'. Journal of Critical Realism 9(1): 33-58.

Elder-Vass, D. 2012. The Reality of Social Construction. Cambridge: Cambridge UP.

Gillespie, T. 2007. Wired Shut: Copyright and the Shape of Digital Culture. Cambridge, MA: MIT Press. Kaidesoja, T. 2009. 'Bhaskar and Bunge on Social Emergence'. Journal for the Theory of Social Behaviour 39(3): 300-22.

Kaidesoja, T. 2013. Naturalizing Critical Realist Social Ontology. Abingdon: Routledge.

Lessig, L. 2004. Free Culture. New York: Penguin.

Morgan, J. 2014. 'What Is Progress in Realism?' Journal of Critical Realism 13(2): 115-38. 
Stanford, K. 2013. Underdetermination of Scientific Theory [web page]. 16 September 2013. http://plato.stanford.edu/entries/scientific-underdetermination/.

Strangelove, M. 2005. The Empire of Mind: Digital Piracy and the Anti-Capitalist Movement. Toronto: University of Toronto Press.

\section{Notes on Contributor}

Dave Elder-Vass is Senior Lecturer in sociology at Loughborough University. His writing on social ontology and social theory includes two recent books: The Causal Power of Social Structures (2010) and The Reality of Social Construction (2012). Currently, he is working on issues in the social ontology of economic phenomena, on the nature of cultural communities, and on giving as an alternative to market exchange.

Correspondence to: Dave Elder-Vass, Department of Social Sciences, Loughborough University, Ashby Road, Loughborough, LE11 3TU, UK. Email: d.elder-vass@lboro.ac.uk 